\title{
Design of Eco Friendly Floating Restaurant for River
}

\author{
Eddy Setyo Koenhardono ${ }^{1}$
}

\begin{abstract}
Monkasel monument is one of Surabaya's landmarks and will become "The Central Business District Riverbank". In this area has been built many recreational facilities, namely the statue of Suro and Boyo, Plaza Area, BMX Area, Tribune Area, Skate Park Area and Food court Ketabang. However, the development of water tourism in this area is still not optimal. One to overcome this is the need to develop a floating restaurant that can integrate all existing facilities, especially the food court. The development of this floating restaurant has multi-function, which is increasing the visitor of the food court, because this floating restaurant only provides a place to eat not sell food, as a place of business transactions and in the long run will improve the water quality of Kalimas river. This floating restaurant is designed with high comfort and safety, and environmentally friendly, so that all the functions can be accommodated well. This is because the floating diner is a catamaran boat that has a low sweep wave and uses solar panels.
\end{abstract}

Keywords_Floating Restaurant, Catamaran, Low Wake Wash, Waterways Transportation.

\section{INTRODUCTION}

In the past, Kalimas river became the main means of transportation for trading activities of valuables from various corners of the Java island. At that time, Kalimas river also has a role as work and marketing spaces for the city of Surabaya [1]. Nowadays, such role has been much degraded, due to changes from the water transportation system mode into land transportation system mode. The Kalimas river only becomes an irrigation channel and a garbage dump for the community along the river.

Therefore, after extensive programs to clean up the river and relocate squatters along the riverbanks, the city government of Surabaya plans to develop the area for recreation as well as cultural functions. The government has planned to revitalize the Kalimas river since 2008, which is divided into 9 regions that have different style and variety.

Monkasel is one region that will become "The Central Business District Riverbank”. There are some recreational facilities had been built, one of them is Ketabang Kali food court. However, facilities that utilize the water media is still not built, such as a floating restaurant that can be operated in the river around the Monkasel area. This floating restaurant can be used as a place to enjoy eating together for visitors or as a business meeting. Since the Kalimas river width is $25 \mathrm{~m}$ and the banks of river is about $0.8 \mathrm{~m}$,

${ }^{1}$ Eddy Setyo Koenhardono is with Department of Marine Engineering, Faculty of Marine Technology, Institut Teknologi Sepuluh Nopember (ITS), Kampus ITS Sukolilo, Surabaya 60111, Indonesia. E-mail: eddykoen@its.ac.id. the floating restaurant should be easy to maneuver, safe, comfortable and environmentally friendly.

This paper aims to design the floating restaurant based on the real condition of the Kalimas river around Monkasel region. Moreover, the good maneuvering, high safety and comfortable, and environmentally friendly must be considered in the design.

\section{LOW WASH CATAMARAN BOAT}

Floating restaurant is a tourism boat that can be used as a place for eating and meetings. As a tourism boat, floating restaurant planning has many consideration factors, namely visitor factor, ship shape and dimension and environmental conditions. Based on visitor factors, this floating restaurant should look beautiful, attractive, safe and comfortable. Judging from the shape and dimensions of the ship, the shape of the vessel must have a high level of stability and low rolling motion as well as dimensions according to the shipping area. From environmental point of view, the ships should be environmentally friendly. Therefore, the characteristics of floating restaurant planned is as follows:

1. Have a beautiful appearance

2. It has a high level of stability and low rolling motion, making it more comfortable

3. Waves generated by the movement of the ship must be as small as possible (low wash displacement craft) because the river wall prone to landslides.

4. To have the capacity and dimensions that correspond to the depth of the river

Based on the characteristics that floating restaurants should have, multi hull boats are more suitable than monohulls. According Dubrovsky, the advantages of multihull vessels compared to mono-hull ships are as follows:

- a large number of choices of types and shapes with various characteristics;

- A larger deck area;

- More or less high seaworthiness;

- Required initial stability without restriction of hull aspect ratio;

- Water-resistant volume above water;

- The possibility of slamming the wet deck;

- Considerable influence of the external charge across the force.

There are some existing guidance to reduce the wave generated by the vessel, such as long skinny lightweight hulls with fine entrance, rounded bottoms, and smooth transition to the stern profile as opposed to heavy, bluntbowed, broad-beamed, flat bottom vessels [2]. Catamaran has several advantages over the other multihull types, 
which are more attractive in terms of accommodation, smaller obstacles and low wake wash. The selection of hull form for the floating restaurant is based on asymmetrical catamaran. The asymmetrical demihull catamaran, with appropriate displacement distribution, hull separation, and fitting hulls with bulbous bow can be another option.[3]-[6]

There are two type of asymmetrical catamaran, which is Flat Side Inwards (FSI) and Flat Side Outwards (FSO). figure 1 shows the resulting wave contour on the asymmetric catamaran FSI and FSO. The Computational Fluids Dynamics numerical simulation produced the wave contour. Figures 2 describes the FSI and FSO configuration wave profiles with the longitudinal wave cut location at the centerline as well the effect of demihull separation ratio (S/L), respectively. A dashed line represents FSI configuration and a continuous line represents FSO configuration.

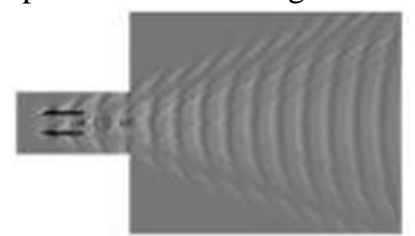

(i) Flat side inwards (FSI)

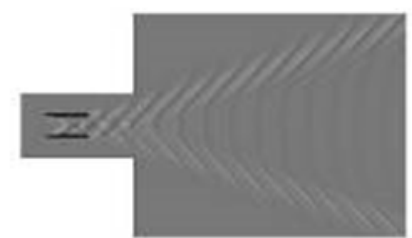

(ii) Flat side outwards (FSO)

Figure 1.Wave contour of FSO \& FSI asymmetric catamaran configuration, L/B of 15.2, S/L of 0.4, Fn of 0.3 [3]-[6]

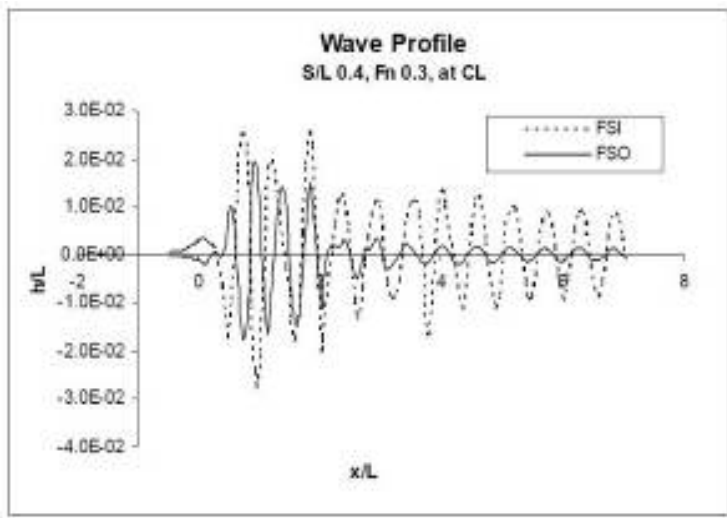

Figure 2. Wave profile comparison between FSI and FSO configuration at centre line longitudinal wave cut [3]-[6]

\section{METHODOLOGY OF RESEARCH}

The methodology used in the research is divided in three activities. Firstly, survey of Kalimas river condition. This survey is done by measuring depth and speed of the Kalimas river flow at some points along the path of the floating restaurant planned. Secondly, the study of literatures related to the hull form of a ship and making of hull form design. Results of the survey become the main consideration in the selection of floating restaurant hull form. Thirdly, calculation of propulsion power, electrical load, and capacity of batterey and solar panel needed for the boat.

\section{RESUlTS AND DisCUSSIONS}

\section{A. "Ketabang Kali" food court}

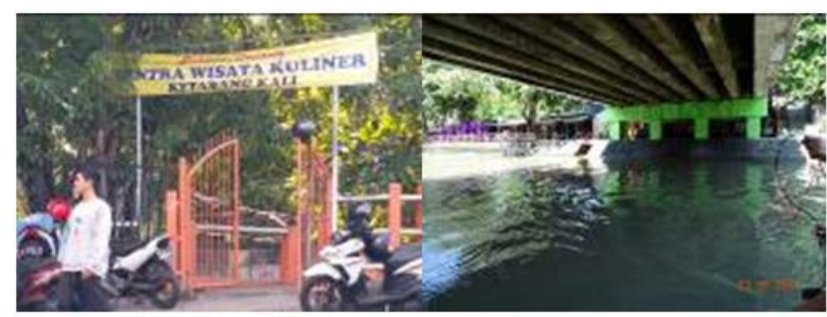

a. Gate of the food court

b. The food court from river side

Figure 3. "Ketabang Kali” food court

"Ketabang Kali" food court is located on the banks of the Kalimas river in Monkasel monument region, as shown in figure 3 , only small number of visitors came to the food court. The floating restaurant planed is expected to increase the number of visitors to the food court. Therefore, along this food court need to be built two boat stops.

The floating restaurant planned sailing from the food court dock to Monkasel location and then back to the food court dock. The distance of this floating restaurant path is approximately 1,600 m. Depth conditions and flow velocity along the path of a floating restaurant are measured directly. Figure 4 shows the point of measurement location, whereas table 1 is the measurement result.

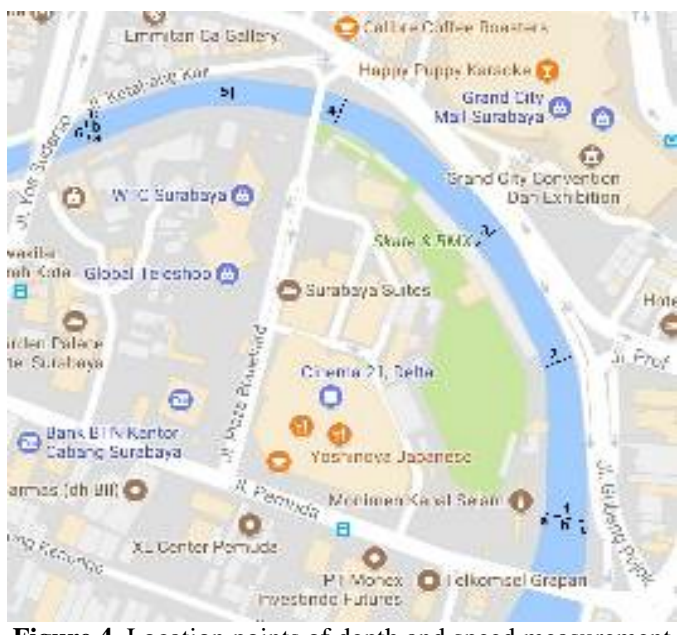

Figure 4. Location points of depth and speed measurement

TABLE 1.

SURVEY OF DEPTH AND SPEED OF KALIMAS RIVER AROUND MONKASEL

\begin{tabular}{|c|c|c|c|c|c|c|c|}
\hline \multirow{2}{*}{\multicolumn{2}{|c|}{ Point }} & \multirow{2}{*}{ Width (cm) } & \multirow{2}{*}{ Depth (cm) } & \multicolumn{4}{|c|}{ Flow velocity (knot) } \\
\hline & & & & 1 & 2 & 3 & 4 \\
\hline \multirow{3}{*}{1} & $\mathrm{a}$ & & 120 & 0.1 & 0.1 & 0.1 & 0.1 \\
\hline & $\mathrm{b}$ & 4100 & 165 & 0.2 & 0.4 & 0.3 & 0.2 \\
\hline & C & & 70 & 0.5 & 0.4 & 0.3 & 0.2 \\
\hline \multirow{3}{*}{2} & $\mathrm{a}$ & & 80 & 0.2 & 0.1 & 0.1 & 0.1 \\
\hline & $\mathrm{b}$ & 2900 & 180 & 0.3 & 0.2 & 0.1 & 0.1 \\
\hline & c & & 110 & 0.2 & 0.3 & 0.3 & 0.2 \\
\hline \multirow{3}{*}{3} & $\mathrm{a}$ & & 85 & 0.4 & 0.3 & 0.3 & 0.2 \\
\hline & $\mathrm{b}$ & 2890 & 180 & 0.4 & 0.5 & 0.4 & 0.3 \\
\hline & c & & 100 & 0.3 & 0.1 & 0.1 & 0.1 \\
\hline \multirow{3}{*}{4} & $\mathrm{a}$ & & 90 & 0.4 & 0.3 & 0.3 & 0.2 \\
\hline & $\mathrm{b}$ & 2860 & 180 & 0.4 & 0.5 & 0.4 & 0.3 \\
\hline & C & & 90 & 0.3 & 0.1 & 0.1 & 0.1 \\
\hline
\end{tabular}


The $3^{\text {rd }}$ International Seminar on Science and Technology

August $3^{\text {rd }}$ 2017, Postgraduate Program Institut Teknologi Sepuluh Nopember, Surabaya, Indonesia

\begin{tabular}{|c|c|c|c|c|c|c|c|}
\hline \multirow{3}{*}{5} & a & \multirow{3}{*}{2450} & 55 & 0.6 & 0.5 & 0.2 & 0.1 \\
\hline & b & & 240 & 0.5 & 0.4 & 0.3 & 0.3 \\
\hline & c & & 100 & 0.1 & 0.1 & 0.1 & 0.1 \\
\hline \multirow{3}{*}{6} & $\mathrm{a}$ & \multirow{3}{*}{2370} & 50 & 0.5 & 0.4 & 0.3 & 0.3 \\
\hline & b & & 190 & 0.4 & 0.3 & 0.4 & 0.4 \\
\hline & C & & 130 & 0.5 & 0.4 & 0.3 & 0.5 \\
\hline
\end{tabular}

\section{B. Floating Restaurant}

Floating restaurant design is a catamaran type boat FSO, because this ship has low wash characteristics. The design of the ship uses a special program for ship design, as shown in Figure 5. The main dimension of the floating restaurant is as indicated below:

$\begin{array}{ll}\mathrm{L}_{\text {overall }} & : 7,0 \mathrm{~m} \\ \mathrm{~L}_{\text {waterline }} & : 6,0 \mathrm{~m} \\ \mathrm{~B}_{\text {overall }} & : 2,8 \mathrm{~m} \\ \mathrm{~B}_{\text {demihull }} & : 0,79 \mathrm{~m} \\ \text { Depth } & : 0,5 \mathrm{~m} \\ \text { Draft } & : 0,29 \mathrm{~m} \\ \text { Displacement } & : 1927 \mathrm{ton}\end{array}$

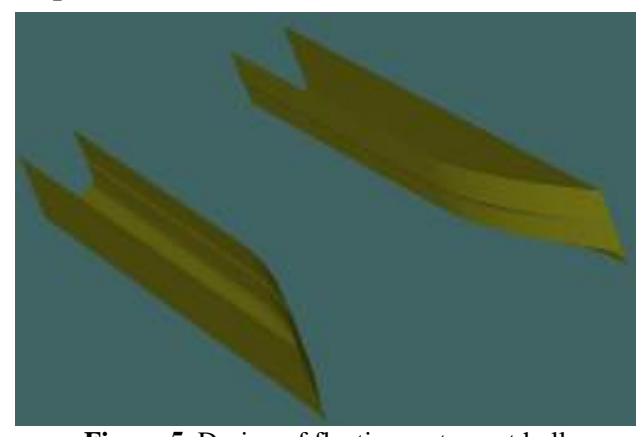

Figure 5. Design of floating restaurant hull

Floating restaurant route is planned to be taken within 1 hour, so the obtained speed is 3 knots. Floating restaurant resistance and power are obtained by using ship design software as shown in table 2.

TABLE 2.

RESISTANCE AND POWER PREDICTION

\begin{tabular}{ccc}
\hline \hline Speed (knot) & Resistance (N) & Power (kW) \\
\hline 0,5 & 7,68 & 0,004 \\
1,0 & 27,66 & 0,026 \\
1,5 & 58,39 & 0,082 \\
2,0 & 98,89 & 0,185 \\
2,5 & 148,32 & 0,347 \\
3,0 & 205,93 & 0,530 \\
3,5 & 271,12 & 0,888 \\
4,0 & 343,48 & 1,285 \\
4,5 & 422,54 & 1,779 \\
5,0 & 509,81 & 2,385 \\
\hline
\end{tabular}

However, the exact power of the driving motor is not available on the market. Therefore, the selected driving motor is the power that approximates the need. The selected driving motor is a type of electric outboard motor, as shown in the Table 3. The propulsion motor is chosen to be smaller than the calculation, since it has an equivalent capability of $1.5 \mathrm{HP}$ petrol outboards.
TABLE 3.

SPESIFICATION OF FLOATING RESTAURANT MOTOR PROPULSION

\begin{tabular}{lll}
\hline & \multicolumn{1}{c}{ Merk } & \multicolumn{1}{c}{ Torqeedo } \\
\cline { 2 - 3 } & Type & Trafel 503 \\
& Input power (w) & 500 \\
Propulsive power (w) & 220 \\
& Nominal voltage (V) & 29,6 \\
& Final charging voltage (V) & 33,6 \\
& Weight (kg) & 8,9 \\
& Shaft length (cm) & 62,5 \\
& Steering & $360^{\circ}$ \\
\hline
\end{tabular}

As a tour ship, the floating restaurant should be beautifully designed, safe, comfortable and environmentally friendly. The three dimensional (3D) design of floating restaurant is shown in Figure 6.

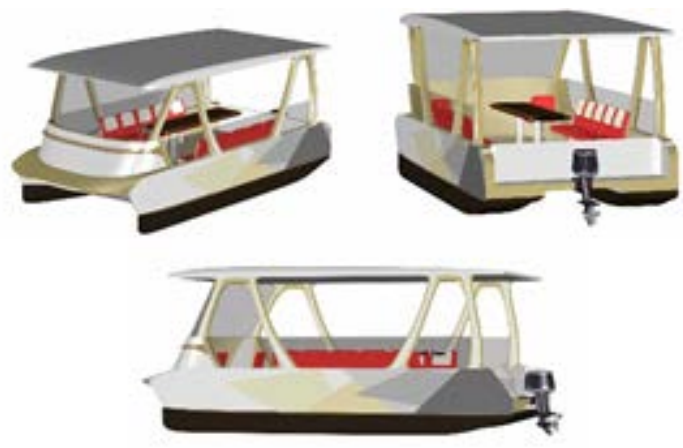

Figure 6. The $3 \mathrm{D}$ design of the floating restaurant

\section{Electric Power System Arrangement}

Electrical systems in the floating restaurants consist of power generation systems, distribution systems and electrical loads. The overall picture of the electrical system can be seen in Figure 7. While more detailed explanations of each component of the electrical system are discussed below:

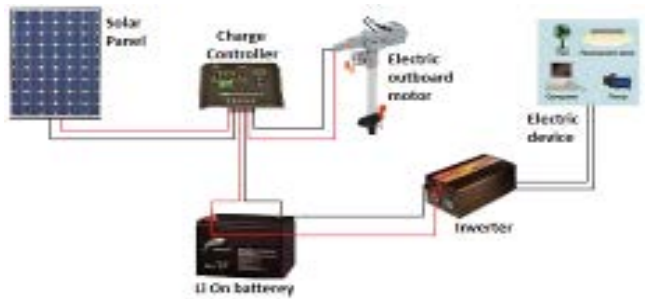

Figure 7. Overview of electrical generation system for floating restaurant 1) Electrical load

This floating restaurant has a function as a place to eat and a place of discussion or meeting, with the operating time from $10 \mathrm{am}$ to $9 \mathrm{pm}$ The electrical load on a floating restaurant is divided into two, namely the AC power load and DC power load. The total DC electric power is 554 watt, while AC power is 165 watt. The whole electrical load specification and their operation length time can be seen in Table 4.

TABLE 4.

ELECTRICAL CALCULATION OF FLOATING RESTAURANT'S LOAD

\begin{tabular}{cccrr}
\hline \hline Name & Specification & No & Op. hour & W.h \\
\hline Outboard motor & $500 \mathrm{~W}, 29.6 / 33.6 \mathrm{VDC}$ & 1 & 10 & 5000 \\
Desktop Mini PC & $45 \mathrm{~W}, 220 \mathrm{VAC}, 50 \mathrm{~Hz}$ & 1 & 10 & 450
\end{tabular}




\begin{tabular}{lllrr} 
Speaker & $40 \mathrm{~W}, 220 \mathrm{VAC}, 50 \mathrm{~Hz}$ & 1 & 10 & 400 \\
Projector & $55 \mathrm{~W}, 220 \mathrm{VAC}, 50 \mathrm{~Hz}$ & 1 & 5 & 275 \\
LED tubes lamp & $9 \mathrm{~W}, 24 \mathrm{VDC}$ & 6 & 4 & 216 \\
Pump & $125 \mathrm{~W}, 220 \mathrm{VAC}, 50 \mathrm{~Hz}$ & 1 & 2 & 250 \\
& Total of electric load & & & 6591 \\
\hline \hline
\end{tabular}

2) Electricity distribution system

The electrical distribution system of the floating restaurant consists of a DC electrical system and an AC power system. As the main source of electricity is the DC system, namely battery. The floating restaurant distribution system diagram is shown in Fig. 7.

\section{3) Electric Generating System}

Sources of electric generating system in floating restaurants consist of energy sources that are continuous and not continuous. Battery as a source of electrical energy that is continuous, so it has an operating capacity for 11 hours. While solar panels are planned to only operate for 4 hours, according to the optimum conditions of the sun in Indonesia. In addition, the floating restaurant is also equipped with a charger that can be used on the condition of solar panels can not charge the battery.

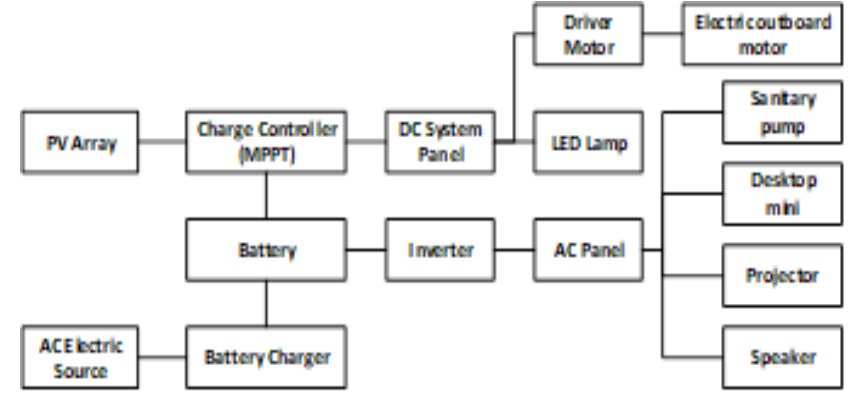

Figure 8. Panel diagram of electric distribution for the floating restaurant

Based on the electrical need calculation in Table 4, the total electrical load requirement in one day is $6,591 \mathrm{Wh}$. The operational efficiency of solar panels is not always at a maximum efficiency condition, due to the loss of stored power or inefficiently collecting solar energy. Even the energy of sunlight produced is not sufficient, due to cloudy weather. Therefore, the calculation of energy needs should be added 25 percent, in order to overcome the lack of maximum solar panels. So the total electrical energy needs to be $8,239 \mathrm{Wh}$.

In Indonesia, maximum sun exposure for 4 hours. So the total requirement of electric energy above will be fulfilled within 4 hours. Within an hour, the installed solar panels will generate electrical energy by $2,060 \mathrm{Wh}$. If the solar panel capacity is selected $80 \mathrm{Wp}$, then the number of solar panels to be installed is 26 panels. These 26 solar panels generate electrical energy of 2,080 Wh per hour or 8,320 Wh for 4 hours.

The energy of 8,320 Wh will be stored in batteries and used to operate the floating restaurant for 11 hours. Type of battery that will be used is dry battery with voltage of $12 \mathrm{~V}$ and capacity of $100 \mathrm{Ah}$. If the energy generated battery is limited to $75 \%$ only, then the required number is 10 batteries.

\section{CONCLUSION}

The proposed Eco Friendly Floating Restaurant is a catamaran ship type of FSO that has the following specifications:

1. Main dimension

$\begin{array}{ll}\text { - Loverall } & : 7.0 \mathrm{~m} \\ \text { - Lwaterline } & : 6.0 \mathrm{~m} \\ \text { - Boverall } & : 2.8 \mathrm{~m} \\ \text { - Bdemihull } & : 0.79 \mathrm{~m} \\ \text { - Depth } & : 0.5 \mathrm{~m} \\ \text { - Draft } & : 0.29 \mathrm{~m} \\ \text { - Displacement } & : 1927 \text { tons } \\ \text { - Speed } & : 3 \text { knots }\end{array}$

2. Motor propulsion system
- Merk
: Torqeedo
- Type
: Trafel 503
- Input power : $: 500 \mathrm{w}$
- Propulsive power : $220 \mathrm{w}$
- Nominal voltage : 29,6 V
- Weight : $8,9 \mathrm{~kg}$
- Shaft length $: 62,5 \mathrm{~cm}$

3. Electrical power plant

- Batterey

o Capacity : $100 \mathrm{Ah}$

o Voltage $: 12 \mathrm{~V}$

o Number : 10

- Solar panel

$\begin{array}{lll}\text { o } & \text { Capacity } & : 80 \mathrm{Wp} \\ \text { o } & \text { Number } & : 26\end{array}$

\section{ACKNOWLEDGEMENT}

This work was financially supported by PTNBH 2017 of Institut Teknologi Sepuluh Nopember.

\section{REFERENCES}

[1] R. Hastijanti, "Developing River Lane as an Alternative for Water Tourism Destination - Case Study: 'Kalimas' River Lane of Surabaya, Indonesia,” in KKU International Engineering, 2014, vol. 931, pp. 781-784.

[2] T. Whittaker, A. Bell, K. M. Morton, M. Shaw, K. Patterson, and M. Surveyor, "An investigation of fast ferry wash in confined waters," in RINA International Conference on Hydrodynamics of High Speed Craft, 1999, p. 13.

[3] O. Yaakob, M. Afifi, A. Mukti, and A. Nasirudin, "A Low Wash Hullform and Pollutant Free Inland Waterways Leisure Craft," in Advances in maritime and naval science and engineering, 2010.

[4] O. B. Yaakob, "The wake wash prediction on an asymmetric catamaran hull form,” 2006.

[5] O. B. Yaakob, M. Afifi, A. Nasirudin, A. Mukti, A. Arizam, and A. Wahab, "Hull form configuration study of a low wake wash catamaran leisure boat," 2007.

[6] O. B. Yaakob, A. Nasirudin, M. P. Abdul Ghani, T. Mat Lazim, M. A. Abd Mukti, and Y. M. Ahmed, "Parametric study of a low wakewash inland waterways catamaran," Sci. Iran., vol. 19, no. 3, pp. 463-471, Jun. 2012. 